\title{
Socioeconomically Informed Use of Geostatistics to Track Adaptation of Resource-Poor Communities to Climate Change
}

\author{
Martin Munashe Chari, Hamisai Hamandawana, and Leocadia Zhou
}

\section{Contents}

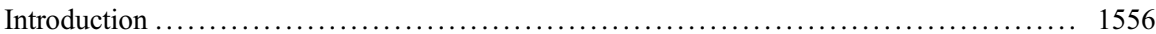

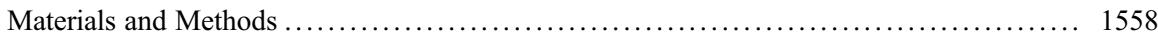

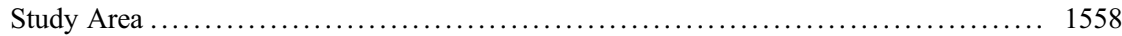

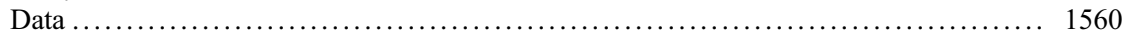

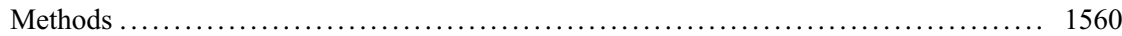

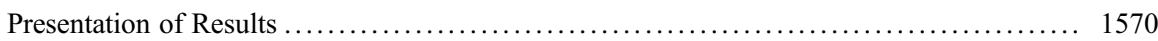

Maps That Were Produced from Data on Water Access, Literacy Levels, and Annual

Income Levels That Were Used to Assess Adaptive Capacity for Years 2001 and 2011 . . 1572

Tables That Show Adaptive Capacity Levels for Individual Communities by Year

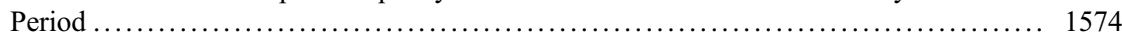

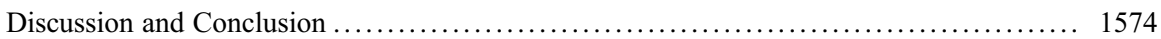

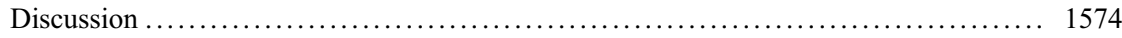

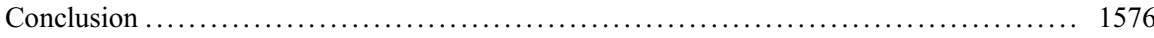

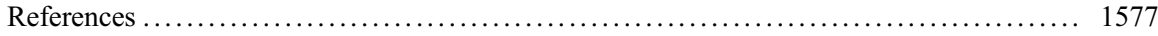

This chapter was previously published non-open access with exclusive rights reserved by the Publisher. It has been changed retrospectively to open access under a CC BY 4.0 license and the copyright holder is "The Author(s)". For further details, please see the license information at the end of the chapter.

M. M. Chari $(\bowtie)$

Department of Geography and Environmental Science, University of Fort Hare, Alice, South Africa

Risk and Vulnerability Science Centre (RVSC), University of Fort Hare, Alice, South Africa e-mail: martinmchari@gmail.com

H. Hamandawana

Department of Geographical Information Systems (GIS) and Remote Sensing, University of Fort Hare, Alice, South Africa

e-mail: hamandawanah@yahoo.com

\section{Zhou}

Risk and Vulnerability Science Centre (RVSC), University of Fort Hare, Alice, South Africa e-mail: Lzhou@ufh.ac.za; zhouleocadia@gmail.com 


\section{Abstract}

As the Green Climate Fund continues to make concerted efforts to leverage funding for resource-constrained communities in the global south under the aegis of increasing climate change impacts in sub-Saharan Africa, there is urgent and compelling need for tools that assist organizations to track the effectiveness of adaptation interventions in reducing vulnerability. This chapter offers a costeffective methodology to track adaptation by using a case-study-based identification of communities with diminishing coping capacities in Raymond Mhlaba Local Municipality in the Eastern Cape Province of South Africa. Multistep geostatistical techniques were utilized in the ArcGIS 10.5 software environment to rank and spatialize changes in adaptation by using demographic census data for the years 2001 and 2011. Results of the analysis revealed that 12 communities had declining or static adaptive capacities between 2001 and 2011, while 10 communities had long-term decrease in adaptive capacities from 2001 to 2011 from a sampling universe of 134 communities. These findings are important because they demonstrate that the methodology can be effectively used to provide actionable information on the prevalence of low adaptation capacities at appropriate temporal and spatial scales, in order to guide the allocation of limited resources to the most deserving communities.

\section{Keywords}

Climate change $\cdot$ Adaptation tracking $\cdot$ Geostatistics $\cdot$ South Africa

\section{Introduction}

Africa is one of the most vulnerable continents to climate change (Sarkodie and Strezov 2019; IPCC 2014; World Bank 2014) due to high dependence of livelihoods on climate-sensitive sectors such as agriculture and forestry, poor infrastructure, and limited adaptive capacities to cope with adverse impacts (Ford et al. 2015). In an effort to overcome these constraints, the Paris Agreement and the Katowice Climate Package have been urging all parties to take more climate action by encouraging the adoption and documentation of appropriate adaptation strategies. Adaptation has been getting increasing recognition as a fundamental component of global-level climate change strategies and investigations (Leal Filho and de Freitas 2018; Brooks 2011; Biesbroek et al. 2010), with sub-Saharan Africa emerging in the limelight (Fox et al. 2018; Jiri and Mafongoya 2017; Leal Filho et al. 2015; Leal Filho et al. 2017; Ziervogel et al. 2014; Dinar et al. 2012) because of growing apprehension of climate risks. This apprehension explains why the Green Climate Fund (GCF) has been increasing levels of adaptation funding to many countries in Africa in order to fulfill the Paris Agreement (Pauw et al. 2018; Tompkins et al. 2018; Georgeson et al. 2016) by enhancing their capacities to mitigate the adverse effects of climate change (Mukarakate 2016). This commitment is demonstrated by the recent extension of 
support to as many as four climate change adaptation projects in South Africa alone (https://www.greenclimate.fund/countries/south-africa). The GCF is part-implementation of the Paris Agreement in the context that "Developed country Parties shall provide financial resources to assist developing country Parties with respect to both mitigation and adaptation in continuation of their existing obligations under the Convention." Because adaptation funding is increasing, tracking progress in its effectiveness is essential in order to identify constraints that need to be addressed and successes that require further strengthening and improvement.

Adaptation tracking is a part of intervention monitoring and assessment that helps to capture the effectiveness with which coping strategies are translated into tangible courses of action that reduce vulnerability to climate change (Berrang-Ford et al. 2019; Lesnikowski et al. 2017). It is also useful in the governing of adaptation actions by providing a baseline for continuous monitoring and evaluation of progress over time (FAO 2017). Although necessity to monitor the advancement of climate change adaptation is gaining increasing recognition, effective tracking continues to be undermined by lack of objective indicators for scoping how adaptation takes place (Ford et al. 2013). This challenge is aggravated by difficulties in quantifying the expression of adaptation tracking due to lack of reliable tools that can be used to identify trends and gaps in adaptation responses. With climate projections pointing to relatively strong rates of warming over Africa (Engelbrecht et al. 2015) and global temperatures rising by an estimated $1.5^{\circ} \mathrm{C}$ above preindustrial levels, it is apparent that there is immediate need to meaningfully embrace climate friendly adaptation strategies (IPCC 2018; New 2018). As atmospheric greenhouse gas concentrations increase in South Africa, an analysis of climate trends, using observations between 1980 and 2016 and IPCC-validated model-simulations up to 2050, projected an increase in global temperatures by $0.02{ }^{\circ} \mathrm{C} /$ year up to 2050 , and a possible increase to $0.03{ }^{\circ} \mathrm{C} /$ year in future (Jury 2019). These scenarios have severe implications for South Africa's climatically vulnerable communities, and there is convincing evidence to support the view that the need to formulate innovative techniques that can be used to monitor the translation of adaptation plans into implementable interventions is long overdue.

In South Africa, Limpopo and Kwa-Zulu Natal provinces are extremely vulnerable to climate change-related problems due to their high dependence on climatesensitive sources of livelihood (Rankoana 2019; Hlahla et al. 2018; Ncube et al. 2016; Gbetibouo et al. 2010). Out of the country's nine provinces, the Eastern Cape is recognized as the most vulnerable (Zhou et al. 2016) because of its susceptibility to consecutive droughts (Ngqakamba 2019; Ndamase 2019; ADM 2010, 2012, 2017; IFRC 2004) with one of the most severe outbreaks being experienced in Amathole District Municipality's (ADM) Raymond Mhlaba Local Municipality (RMLM) during the 2018/19 season (Ndamase 2019). The severity of this drought is demonstrated by four of the six local municipalities under ADM's jurisdiction namely: RMLM, Mbhashe, Mnquma, Ngqushwa that received two water trucks each, while the remaining two; namely Great Kei and Amahlathi, received one truck each (Dwesini 2018). Despite the increasing incidence of droughts in RMLM, the implementation of effective climate change adaptation strategies is still ineffective and continues to be undermined by conspicuous absence of reliable adaptation 
tracking techniques (ADM 2017). These bottlenecks and challenges justify the need for a methodology that can be used to effectively track adaptation. Although demographic indicators provided in numerical format are useful measures of adaptation (Gamble et al. 2013; van Aalst et al. 2008; Wall and Marzall 2006), they are often inadequately exploited because they require a lot of computational manipulations before they can be translated into spatially intelligible information which can be used to direct attention to areas in need of support (Qiu et al. 2019; de Sherbinin 2016; Schensul et al. 2013).

This limitation is aggravated by the fact that most national-level reports on adaptation tend to present critical information in the form of spatially disjointed metrics that can be used more effectively by presenting them in coherent formats that are capable of directing practitioners to specific target areas when action is required. A structured consolidation of these fragmented regional scale observations into discrete geographical localities is therefore essential and helpful because it provides for bottom-up scientific investigations in which the local informs the regional by facilitating exhaustive interrogation of cause-and-effect relationships and identification of areas where action is needed (Hamandawana et al. 2008). The strength of this approach is demonstrated by the Paris Agreement's adoption of an inclusive agenda on what countries can do with climate change (Conway et al. 2019; Kuwornu 2019) by using grassroots strategies that promote effective implementation of adaptation strategies (Keskitalo and Preston 2019). Mindful appreciation of this inclusiveness is demonstrated by Chari et al. (2018); Bouroncle et al. (2017); Weis et al. (2016); and Juhola and Kruse (2015) who provide useful examples of approaches that can be used to promote adaptation by aiding objective identification of communities that are vulnerable to the adverse effects of climate change.

Although RMLM has not been very successful in attracting support for adaptation initiatives, evidence suggests that local communities in this area are increasingly being exposed to climate-driven short-term variabilities that are considered to be more important stimuli to adaptive responses than long-term changes in climate (Berrang-Ford et al. 2011). Unfortunately, it has not been possible for resource-poor communities in this area and others elsewhere to access meaningful assistance due to lack of local-level information that can be used to delimit localities in need of external support (Taylor 2016). This chapter attempts to demonstrate how this gap can be bridged by providing an adaptable and spatially explicit case-study-based methodology to track the extent to which local communities in RMLM have been able to meaningfully embrace climate-friendly adaptation.

\section{Materials and Methods}

\section{Study Area}

Raymond Mhlaba (Fig. 1) is a sparsely populated $\left(\sim 24\right.$ people $\left./ \mathrm{km}^{2}\right)$ countryside local municipality comprising 23 wards that cover approximately $6,358 \mathrm{~km}^{2}$ (ADM 2017). 

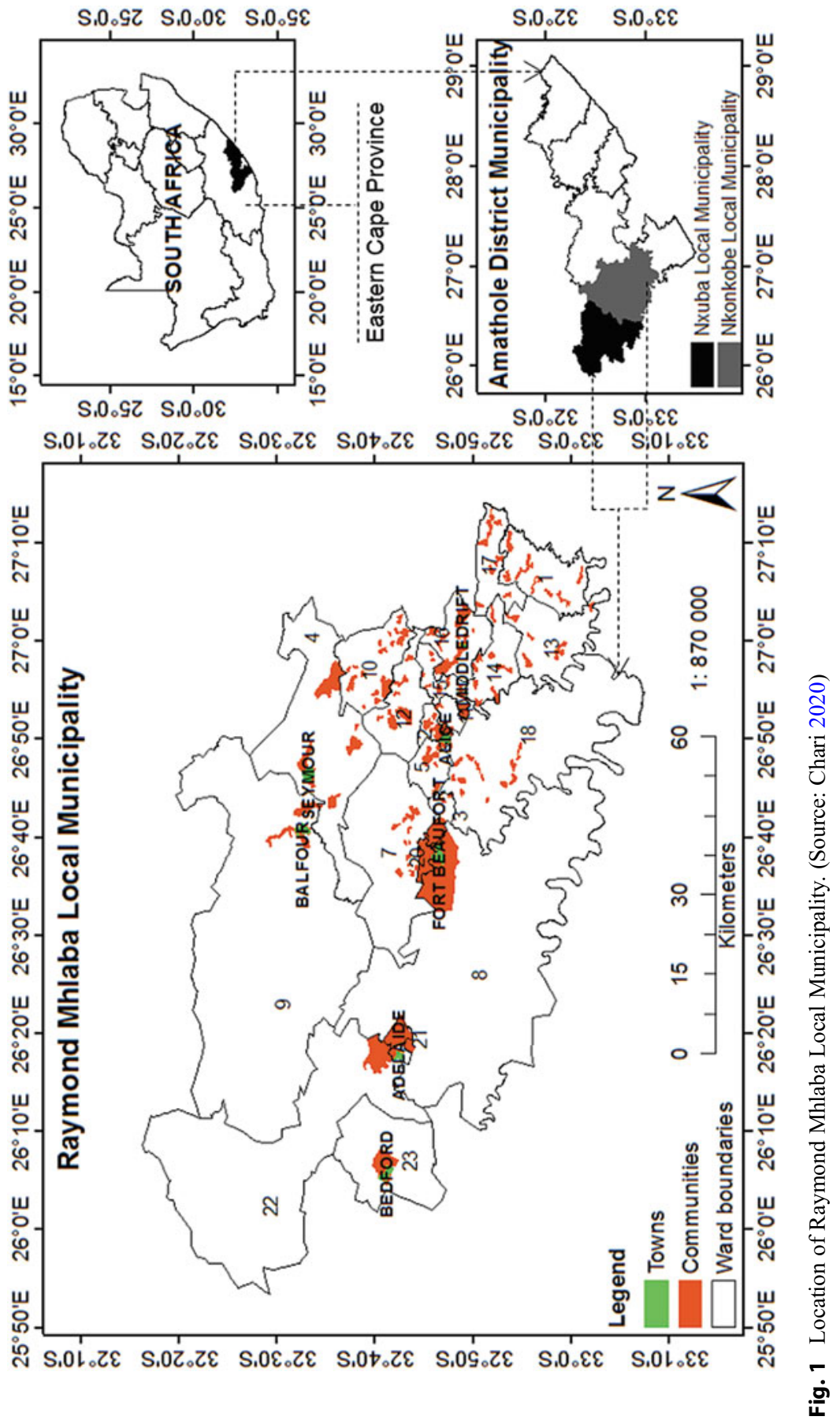
It became the largest of ADM's six local municipalities when it was established by merging Nkonkobe and Nxuba Local Municipalities after the August 2016 local elections (Local Government Handbook 2016). The majority of villages in this area are situated in the immediate peripheries of Fort Beaufort (Fig. 1) with this positioning being largely influenced by accessibility to the latter's urban amenities and availability of arable land for subsistence farming. The entire municipality has a semiarid climate that is characterized by a) unreliable seasonal autumn rainfall which does not exceed $600 \mathrm{~mm} /$ annum with the lowest $(\sim 7 \mathrm{~mm})$ and highest $(\sim 66 \mathrm{~mm})$ amounts occurring in July and March, respectively, and b) average mid-day temperatures that range from $19.3{ }^{\circ} \mathrm{C}$ in June to $28.3^{\circ} \mathrm{C}$ in January (www.statssa.gov.za). The abilities of this area's local communities to adapt to deteriorating climatic conditions are severely undermined by unreliable rainfall which makes rain-fed subsistence crop production extremely risky. This limitation and the municipality's documented failure to attract substantial adaptation funding and its positioning in a hotspot area with resource-poor households that are projected to experience widespread climate-change induced decrease in crop yields (Ncube et al. 2016) make it a suitable target for a case study-based exploration of novel techniques that can be used to boost adaptation tracking.

\section{Data}

The datasets that were used in this study were compiled by sourcing information from different sources over different time periods between January 2017 and May 2019. These datasets include (a) a shapefile that captures the distributions of local communities in RMLM as compiled by Statistics South Africa (StatsSA) in 2011, (b) 2001 and 2011 census data in a raw Microsoft Excel table format that was provided by the same source, and (c) insights of expert informants that were used to verify the reliability and appropriateness of the municipal-level data that was used in this study. Availability of census data for the years 2001 and 2011 was judged to be timely because these records provided demographic indicators over a 10-year period which was reasoned to be long enough for individual households to translate climatechange-induced coping strategies into quantifiable indicators of adaptation. These datasets were also considered to be reliable because in South Africa, StatsSA is the custodian of official multilevel planning statistics (www.statssa.gov.za).

\section{Methods}

A hybrid approach comprising a multistep GIS-based mapping and analysis of aggregated indicators was used to track the adaptation of resource-poor communities to climate change with adaptive capacity indicators being purposefully selected to accommodate representative inclusion of different communities and the singular geographical and socioeconomic distinctions of their localities. The Nkonkobe Integrated Development Plan (IDP) of 2012-2017 was used to aid the identification 
of communities with different livelihood activities because most of the communities in RMLM reside in the former Nkonkobe Local Municipality (Fig. 1). The selection of assessment indicators was based on the definition of adaptive capacity provided by Heltberg and Bonch-Osmolovskiy (2011) and the type and level of demographic data available for the municipality with further refinements being made by using ancillary information that was solicited from expert informants. Overall, the indicators listed and described in Table 1 below were finally selected on the basis of the logic described above and used to assess and map adaptive capacities in the municipality.

Prior to analysis, spreadsheets with information on sub-places/communities were cleaned by (1) deleting unnecessary details from all Excel datasets and (2) selecting matching names in the 2001 and 2011 census records to facilitate the execution of

Table 1 Description of demographic indicators used for assessing and tracking adaptation

\begin{tabular}{|c|c|c|}
\hline $\begin{array}{l}\text { Narrative } \\
\text { indicator }\end{array}$ & Rationale & $\begin{array}{l}\text { Ranking/classification of } \\
\text { communities }\end{array}$ \\
\hline $\begin{array}{l}\text { Literacy } \\
\text { levels }\end{array}$ & $\begin{array}{l}\text { Specified adaptive capacity within the } \\
\text { communities on basis of highest education } \\
\text { level. Reclassified from } 21 \text { classes to } 6 \\
\text { classes. }\end{array}$ & $\begin{array}{l}\text { Scores of } 0 \text { to } 5 \text { were allocated as } \\
\text { follows on the basis of level of } \\
\text { education: No schooling }=0 \text {, Some } \\
\text { Primary }=1 \text {, Completed } \\
\text { Primary }=2 \text {, Some Secondary }=3 \text {, } \\
\text { Completed Secondary }=4 \text {, } \\
\text { Higher }=5 \text {. }\end{array}$ \\
\hline $\begin{array}{l}\text { Income } \\
\text { levels }\end{array}$ & $\begin{array}{l}\text { Communities with low incomes have low } \\
\text { resilience because they are unlikely to } \\
\text { have access to credit. Reclassified from } 12 \\
\text { classes to } 5 \text { classes. }\end{array}$ & $\begin{array}{l}\text { Scores of } 0 \text { to } 4 \text { were allocated } \\
\text { depending on income profiles. } \\
\text { Wards with the lowest incomes } \\
\text { were allocated a score of } 0 \text {. Groups } \\
\text { were segregated according to } \\
\text { annual income as follows: No } \\
\text { income }=0, \mathrm{R} 1-\mathrm{R} 9600=1, \mathrm{R} 9 \\
601-\mathrm{R} 19200=2, \mathrm{R} 19201-\mathrm{R} 38 \\
400=3, \geq \mathrm{R} 38401=4 .\end{array}$ \\
\hline \multirow[t]{2}{*}{$\begin{array}{l}\text { Age } \\
\text { profiles }\end{array}$} & \multirow[t]{2}{*}{$\begin{array}{l}\text { Used to identify communities with low } \\
\text { resilience to climate change by virtue of } \\
\text { being economically inactive due to } \\
\text { predominance of children and/ or old } \\
\text { people in the population. Reclassified from } \\
18 \text { classes to } 4 \text { classes. }\end{array}$} & $\begin{array}{l}\text { Scores of } 0 \text { to } 3 \text { were allocated and } \\
\text { communities segregated into three } \\
\text { age groups as follows: } 0-14: \text { Child } \\
\text { (score of } 0), 15-39: \text { Young (score of } \\
\text { 2), } 40-59: \text { Old (score of } 3 \text { ): } * \text { Senior } \\
\text { citizen } 60+(\text { score of } 1) .\end{array}$ \\
\hline & & $\begin{array}{l}\text { * This categorization is based on } \\
\text { age criteria used by South Africa } \\
\text { Social Security Association } \\
\text { (SASSA) to identify beneficiaries of } \\
\text { social security assistance }\end{array}$ \\
\hline $\begin{array}{l}\text { Water } \\
\text { access by } \\
\text { source type }\end{array}$ & $\begin{array}{l}\text { Specified adaptive capacities of individual } \\
\text { communities on the basis of most used } \\
\text { water sources. Reclassified from } 7 \text { classes } \\
\text { to } 4 \text { classes. }\end{array}$ & $\begin{array}{l}\text { Other sources }=0, \text { Surface } \\
\text { water }=1, \text { Ground water }=2, \\
\text { Regional water scheme }=3\end{array}$ \\
\hline
\end{tabular}

Source: Adapted from Chari et al. (2018) 
valid geospatial analysis operations. To avoid join operation errors in ArcGIS 10.5, all communities that were founded after year 2001 and all extra spaces in the attribute tables of the community names field (key fields) were omitted from the spreadsheet of 2011. Thereafter, shapefiles were created by linking each input indicator's Excel table to the attribute table of the digitized-communities shapefiles and the Join operation used to translate these datasets into spatial layers that were combined with other layers to provide thematic map-portrayals of adaptive capacity ranks. The demographic data from StatsSA was analyzed at community level because this was the lowest level at which required data was available. The combination of layers was followed by turning off repeated fields in the output attribute tables in order to mute field redundancies when the data was exported to the geodatabase. In the final step the following Python script (Script 1) was used to automatically assign scores to communities in the income levels attribute table, and the three indicators (Literacy levels, Source of water, Age profiles) for census years 2001 and 2011 after changing their table names, field names, and row numbers, following the criteria in Table 1 .

\section{Script 1 Script That was Used to Automatically Assign Scores for Community Income Levels}

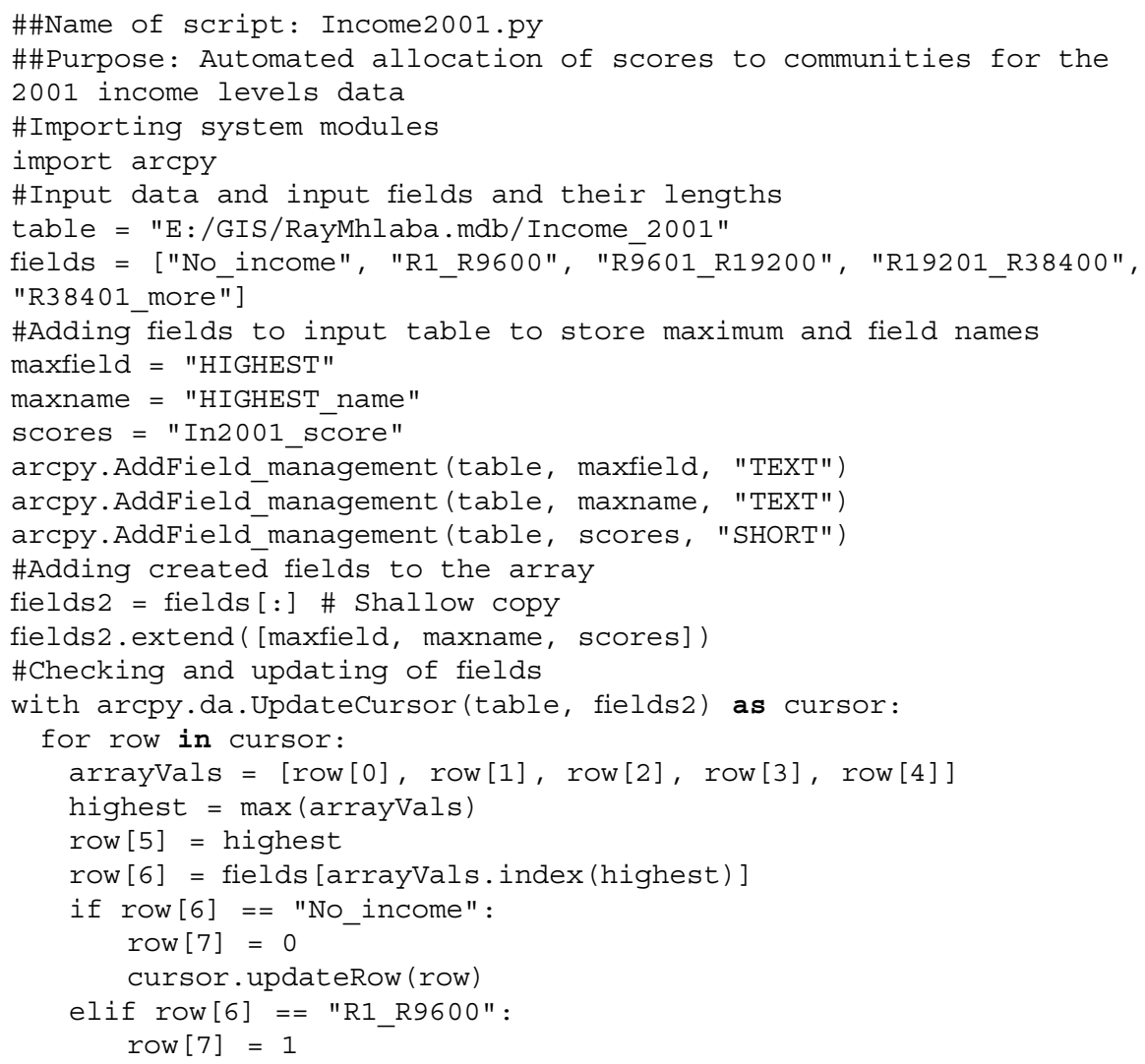




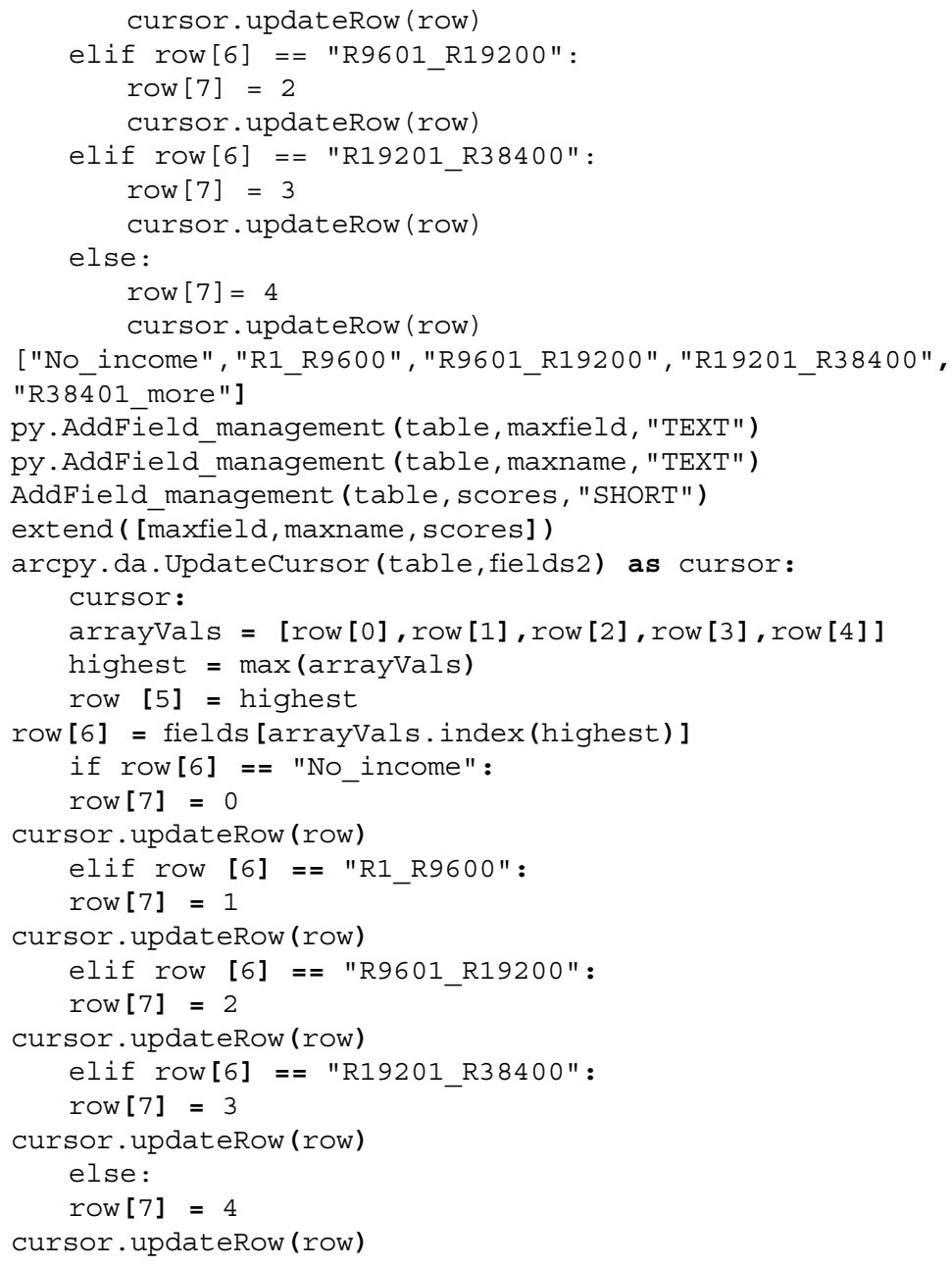

Script 1 was executed by using the Python execfile command to generate a map for each of the four indicators in ArcMap 10.5 for years 2001 and 2011 on the basis of the assigned scores in order to reveal spatial variations in each indicator with communities that had the lowest scores for each indicator being identified by examining all attribute tables. Adaptive capacity scores for both census years (Table 2) were automatically determined by generating a new shapefile and attribute table into which the previously calculated scores from the four indicators for each community were imported and automatically summed up by using Script 2 and Script 3. Although all indicators were weighted equally because of limited availability of indicator data for the municipality, this relaxation did not compromise the reliability of results because information obtained from expert informants and the Nkonkobe IDP for 2012-2017 (Nkonkobe Local Municipality 2012) confirmed that 
Table 2 Evaluation of adaptive capacity in the attribute table for each of the census years

\begin{tabular}{l|l|l|l|l|l|l|l}
\hline Village & $\begin{array}{l}\text { Ward } \\
\text { number }\end{array}$ & $\begin{array}{l}\text { Access to } \\
\text { water }\end{array}$ & $\begin{array}{l}\text { Literacy } \\
\text { levels }\end{array}$ & $\begin{array}{l}\text { Income } \\
\text { levels }\end{array}$ & $\begin{array}{l}\text { Age } \\
\text { profile }\end{array}$ & $\begin{array}{l}\text { Adaptive } \\
\text { score }\end{array}$ & $\begin{array}{l}\text { Adaptive } \\
\text { capacity }\end{array}$ \\
\hline $\mathrm{V}_{1}$ & $\mathrm{~W}_{1}$ & 3 & 5 & 4 & 3 & 15 & HIGH \\
\hline $\mathrm{V}_{2}$ & $\mathrm{~W}_{2}$ & $\mathrm{~S}_{1}$ & $\mathrm{~S}_{2}$ & $\mathrm{~S}_{3}$ & $\mathrm{~S}_{4}$ &. &. \\
\hline$\cdot$ &. &. &. &. &. &. &. \\
\hline$\cdot$ &. &. &. &. &. &. &. \\
\hline $\mathrm{V}_{134}$ & $\mathrm{~W}_{23}$ & 3 & 3 & 2 & 0 & 8 & MEDIUM \\
\hline
\end{tabular}

$\mathrm{V}_{1} \ldots \mathrm{V}_{134}$ - community names; $\mathrm{W}$ - ward numbers; $\mathrm{S}_{1}, \mathrm{~S}_{2}, \mathrm{~S}_{3}, \mathrm{~S}_{4}$ - indicator scores. Adaptive scores ranged from $1-15$

Source: Adapted from Chari et al. (2018)

all indicators were equally important for adaptive capacity assessment. Adaptive capacities for the census years 2001 and 2011 were calculated in the attribute table (Table 2) by using the following formula:

$$
\text { Adaptive score }=\left(\sum_{n=s 1}^{s 4} n\right)
$$

Where $S_{1}, S_{2}, S_{3}, S_{4}$ are scores for each of the four indicators

The following Python script (Script 2) was used to automatically create a new shapefile and attribute table and to join, Age_Profile scores to the IndicatorScores table. The same script was also used to join the remaining three indicator scores to the IndicatorScores attribute table by using community name as the linking field.

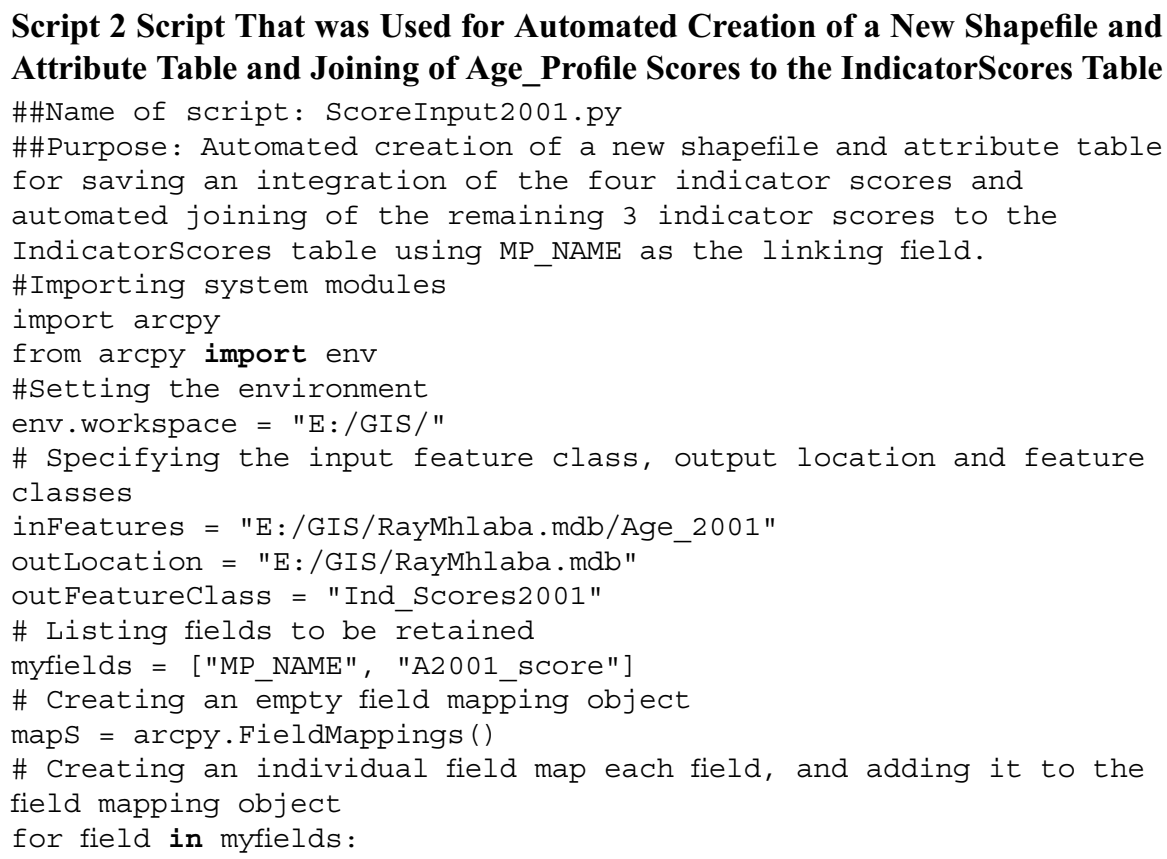
Attribute Table and Joining of Age_Profile Scores to the IndicatorScores Table 
map $=$ arcpy.FieldMap ()

map.addinputField(inFeatures, field)

maps . addFieldMap (map)

\# Copying the feature class using the fields

arcpy.FeatureClassToFeatureclass_conversion (inFeatures,

outLocation, outFeatureclass, field mapping=maps)

\#Joining the remaining 3 indicator scores for different fields into one table

arcpy.Joinfield management("Ind Scores2001", "MP NAME",

"Income_2001", "MP_NAME", "In2001_score")

arcpy.Joinfield_management("Ind_Scores2001", "MP_NAME",

"Literacy_2001", "MP_NAME", "Lit̄2001_score")

arcpy.Joinfield_management("Ind_Scores2001", "MP_NAME",

"Water_2001", "MיPP_NAME", "W2001_score")

arcpy import env

\#Setting the environment

env. workspace = "E:/GIS/"

\# Specifying the input feature class, output location and

feature classes

inFeatures = "E:/GIS/RayMhlaba.mdb/Age_2001"

outLocation = "E:/GIS/RayMhlaba.mdb"

outFeatureClass = "Ind_Scores2001"

\# Listing fields to be retained

myfields = ["MP_NAME", "A2001_score"]

\# Creating an empty field mapping object

maps $=$ arcpy. FieldMappings ()

\# Creating an individual field map each field, and adding it to

the field mapping object

for field in myfields:

$\operatorname{map}=\operatorname{arcpy} \cdot$ FieldMap ()

map.addInputField (inFeatures, field)

maps . addFieldMap (map)

\# Copying the feature class using the fields

arcpy.FeatureClassToFeatureClass_conversion (inFeatures,

outLocation, outFeatureClass, field_mapping=maps)

\#Joining the remaining 3 indicator scores for different fields

into one table

arcpy.Joinfield_management

( "Ind_Scores2001", "MP_NAME", "Income_2001", "MP_NAME",

"In2001_score")

arcpy.Joinfield_management

("Ind_Scores2001", "MP_NAME", "Literacy_2001", "MP_NAME", "Lit2001_score")

arcpy.Joinfield_management

("Ind_Scores2001","MP_NAME", "Water_2001", "MP_NAME", "W2001_score")

Since the highest attainable adaptive capacity score from addition of the four highest indicator scores was 15 (Table 1), the computed adaptive capacity scores were ranked into low-medium-high adaptive capacity as follows: 1-5 = LOW, 6-10 $=$ MEDIUM, and 11-15 = HIGH by using the Python execfile command to run the following Python script (Script 3) which automatically added a field for the ranked adaptive capacity scores attribute table. 


\section{Script 3 Script That Was Used for Joining of the Remaining 3 Indicator Scores to the IndicatorsScores Table Using MP_NAME as the Linking Field}

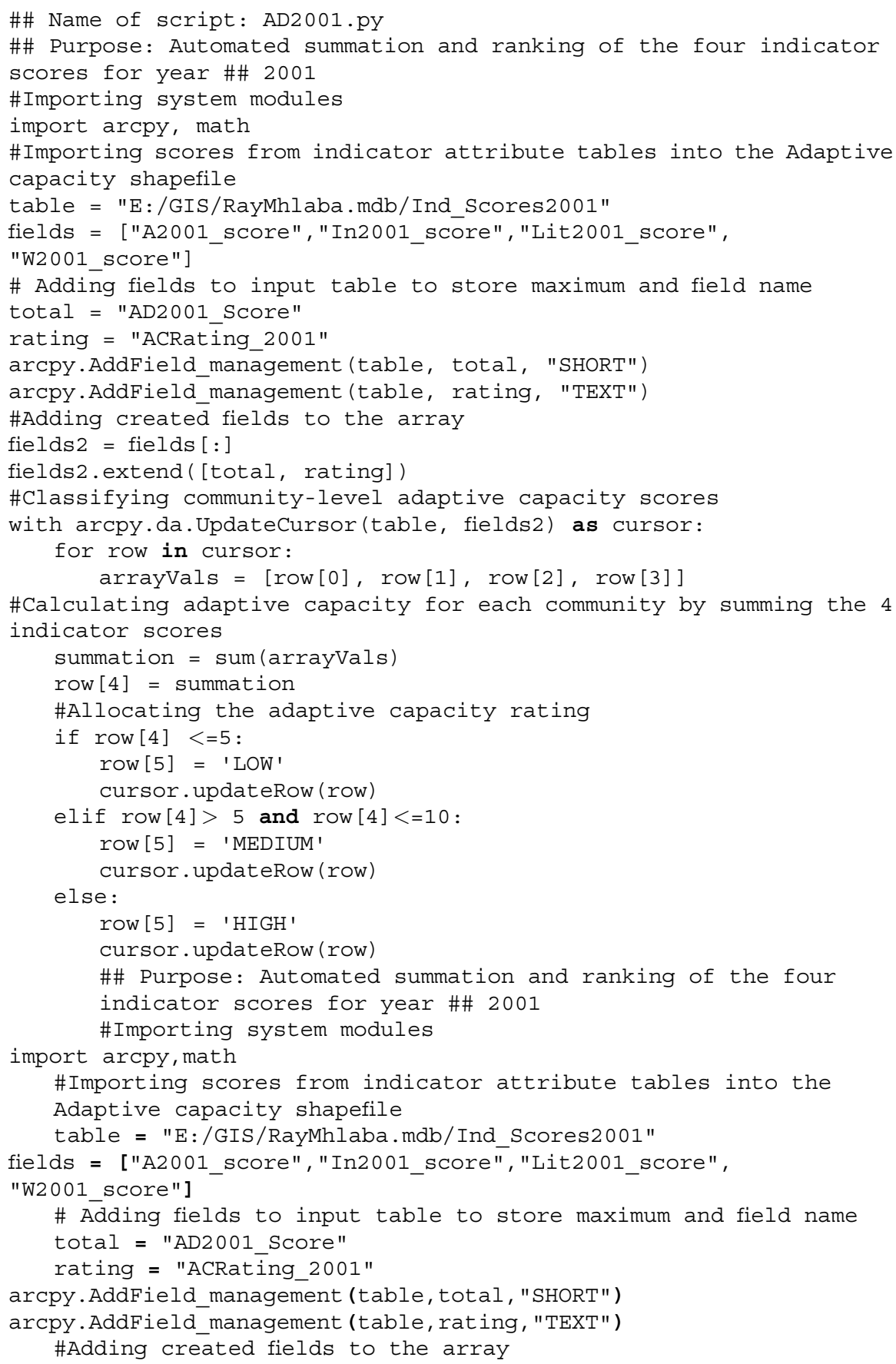




\section{fields2 = fields $[:]$}

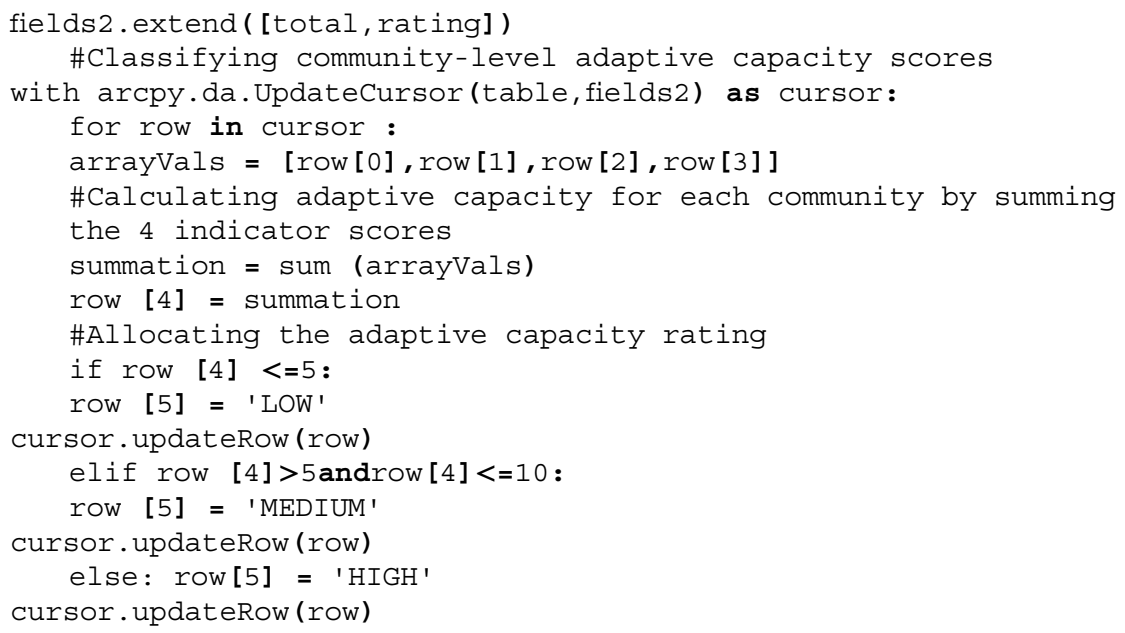

An adaptive capacity map was generated in ArcMap 10.5 from the rankings that were obtained for each of the two census years and the following Python script (Script 4) subsequently used to automatically create a new shapefile and to save adaptive capacities from the indicator scores tables for years 2001 and 2011 in one attribute table (Table 3).

\section{Script 4 Script That Was Used for Joining of the Remaining 3 Indicator Scores to the IndicatorsScores Table Using MP_NAME as the Linking Field}

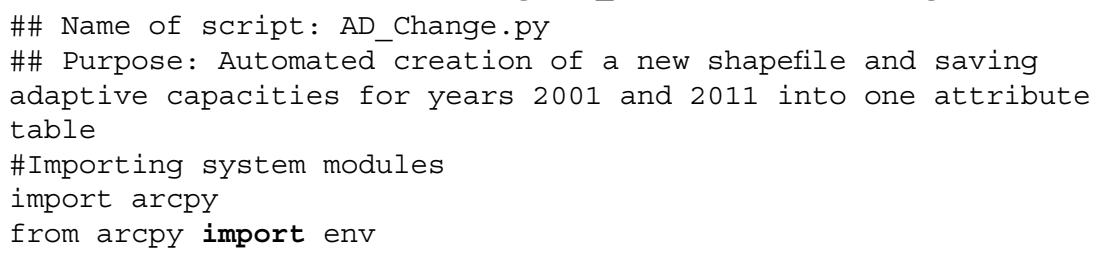

Table 3 Evaluation of changes in adaptive capacity scores between census years 2001 and 2011

\begin{tabular}{|c|c|c|c|c|c|}
\hline \multirow[b]{2}{*}{ Village } & \multirow[b]{2}{*}{ Ward number } & \multicolumn{2}{|c|}{ Adaptive score } & \multirow[b]{2}{*}{ Difference } & \multirow[b]{2}{*}{ Rating } \\
\hline & & 2011 & 2001 & & \\
\hline $\mathrm{V}_{1}$ & $\mathrm{~W}_{1}$ & 5 & 8 & -3 & DECREASE \\
\hline $\mathrm{V}_{2}$ & $\mathrm{~W}_{2}$ & $\mathrm{~A}_{1}$ & $\mathrm{~A}_{2}$ &. & - \\
\hline . & . & . & . & . & . \\
\hline . & . & . & . & . & . \\
\hline $\mathrm{V}_{134}$ & $\mathrm{~W}_{23}$ & 12 & 8 & 4 & INCREASE \\
\hline
\end{tabular}

$\mathrm{V}_{1} \ldots \mathrm{V}_{134}$ - community names; $\mathrm{W}$ - ward numbers; $\mathrm{A}_{1}, \mathrm{~A}_{2}$ - adaptive capacity scores for year 2011 and year 2001, respectively

Source: Chari 2020 


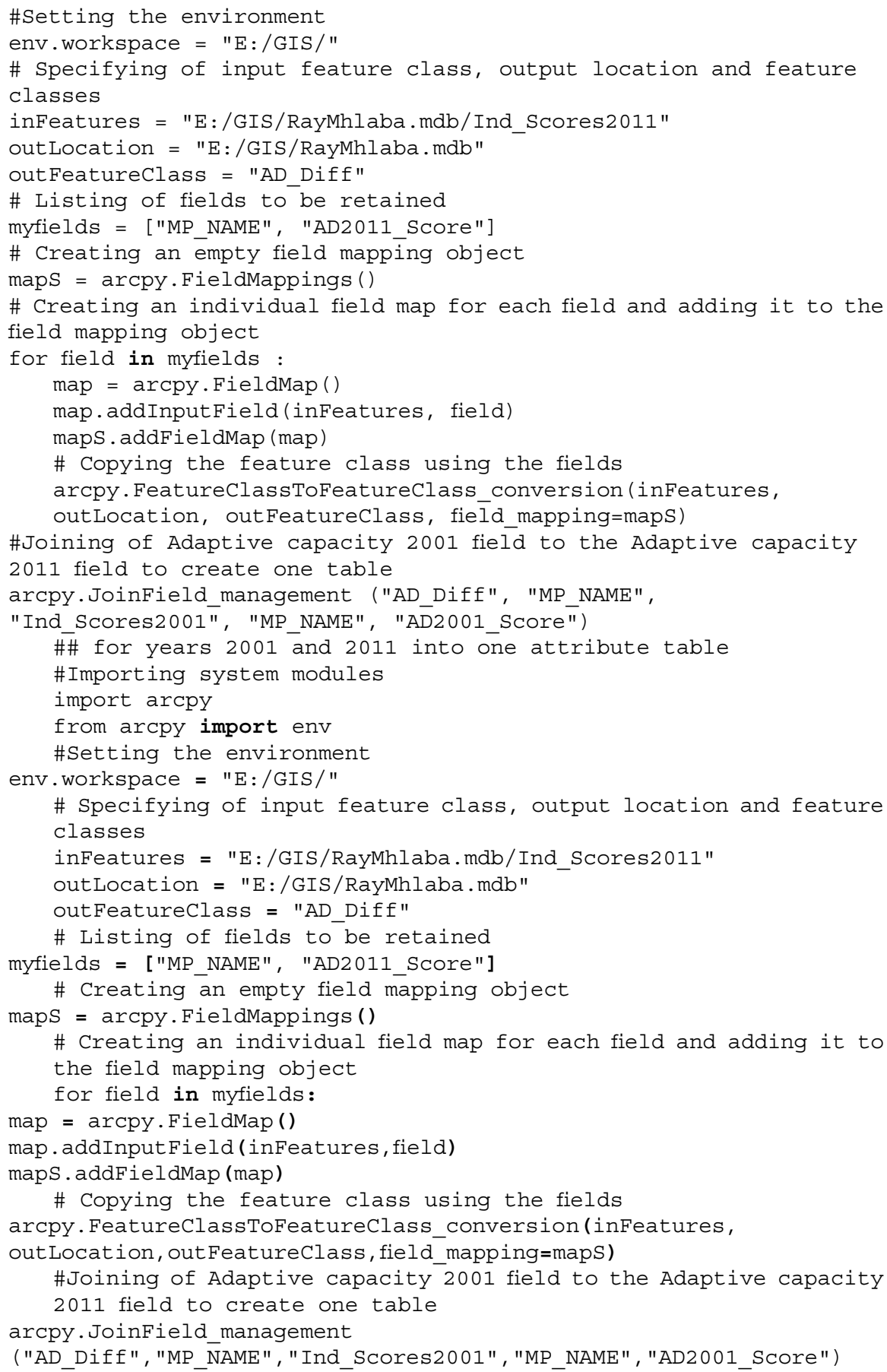


Changes in adaptive capacity scores between census years 2001 and 2011 (Table 3) were calculated by using the following formula:

$$
\text { Change in adaptive capacity }=\left(\begin{array}{c}
2011 \\
\sum_{n=s 1}^{s 4} n
\end{array}\right)-\left(\begin{array}{c}
2001 \\
\sum_{n=s 1}^{s 4} n
\end{array}\right)
$$

The adaptive capacity scores were automatically ranked into no change, decrease, and increase as follows: Difference of $0=$ NO CHANGE; Difference of $\leq-1=$ DECREASE; Difference of $\geq 1=$ INCREASE by using the following Python script (Script 5) that was run by executing the Python execfile command which also generated fields for differences and ratings of adaptive capacity scores for the two census years and automatically added them to the attribute table.

\section{Script 5 Script That Was Used for Calculating Changes in Adaptive Capacities Between 2001 and 2011}

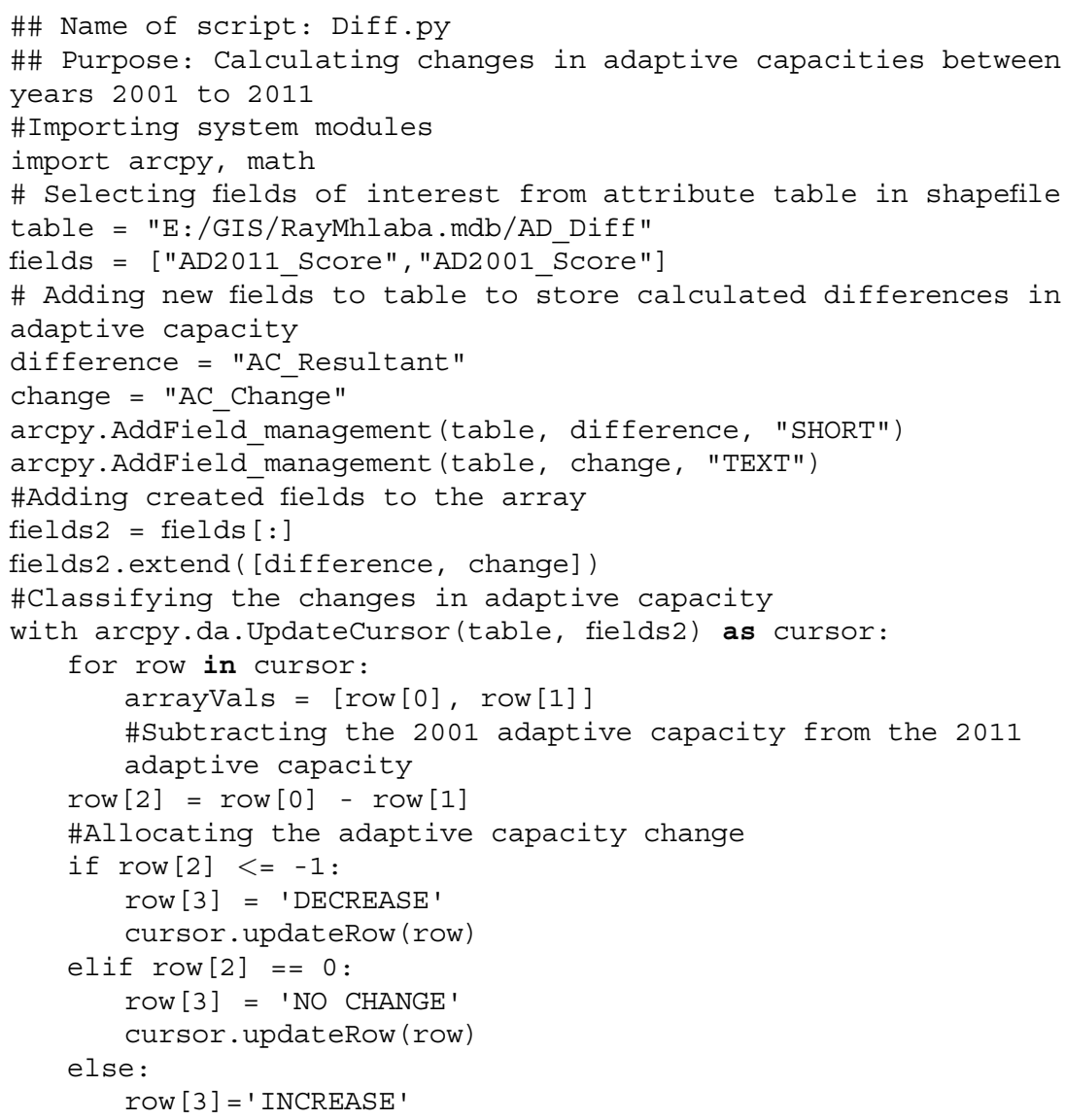




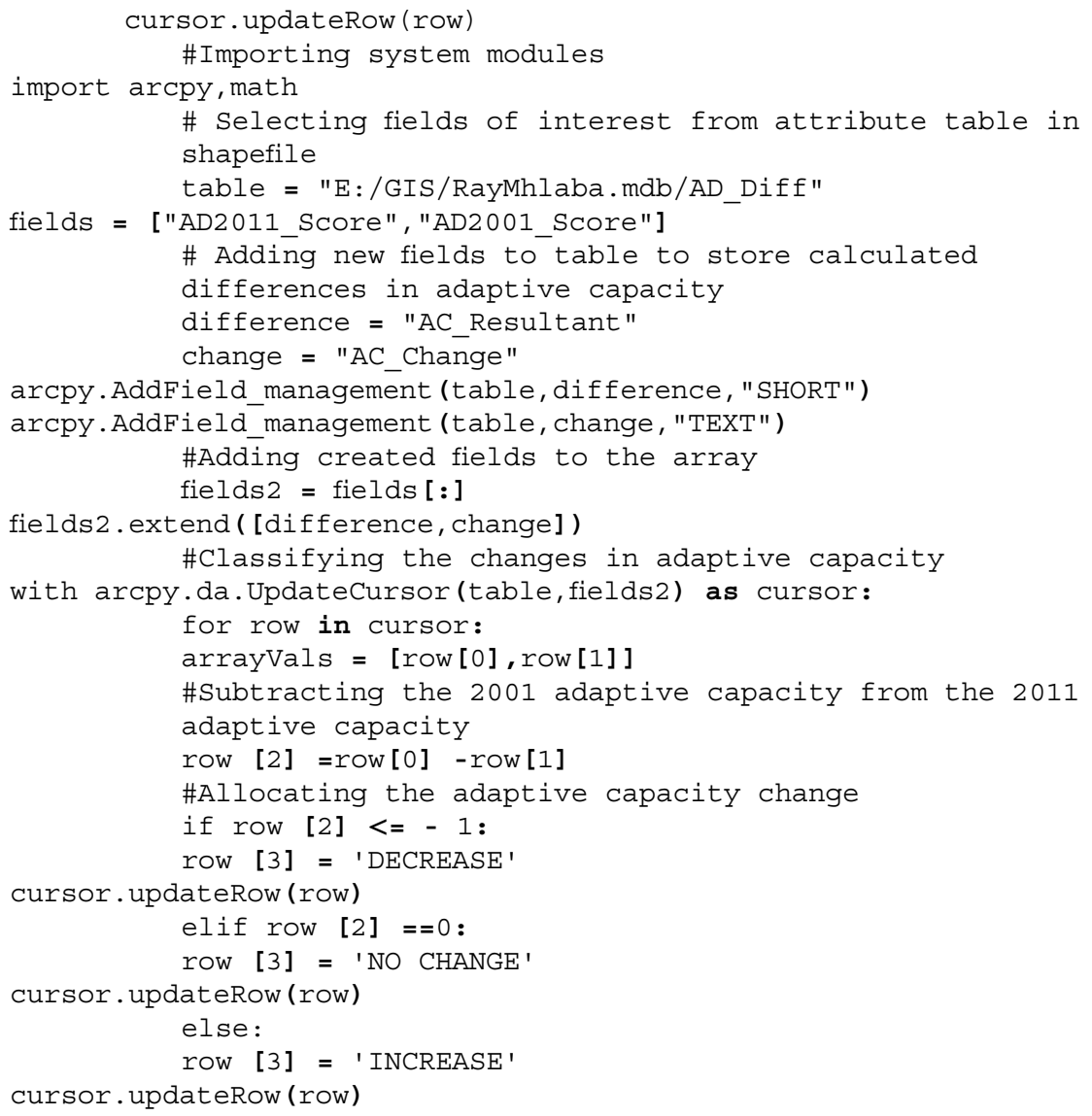

A map showing changes in adaptive capacities was produced in ArcMap 10.5 based on the rankings and another map showing communities with low adaptive capacities by year 2011 produced from the 2011 adaptive capacity attribute table. Thereafter, the same attribute table and platform were used to generate a list of communities with decreased adaptive capacities over the 10 years between 2001 and 2011.

\section{Presentation of Results}

Results of this study are presented in the form of (1) maps that were purposefully designed to illustrate how tabulated data can be portrayed in a visually comprehensible manner that facilitates better tracking of adaptation compared to conventional presentation of this important information in the form of tables and histograms that do not capture the spatial dimension (Figs. 2, 3, and 4) and (2) tables that summarize communities that were identified as having declining/static adaptive capacities and 

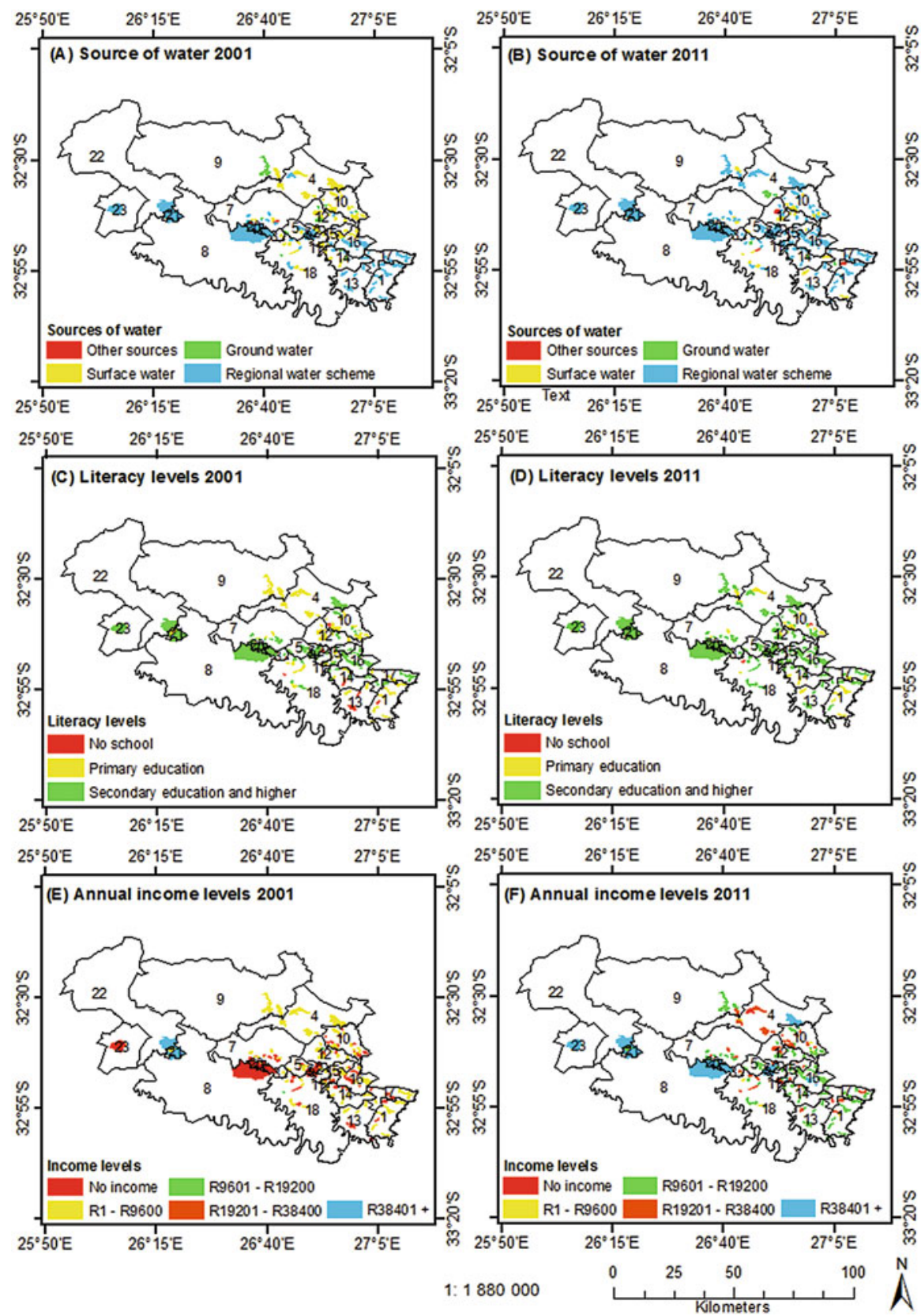

Fig. 2 Access to water by source type, literacy, and annual income levels for communities in RMLM in 2001 and 2011. (Source: Chari 2020) 


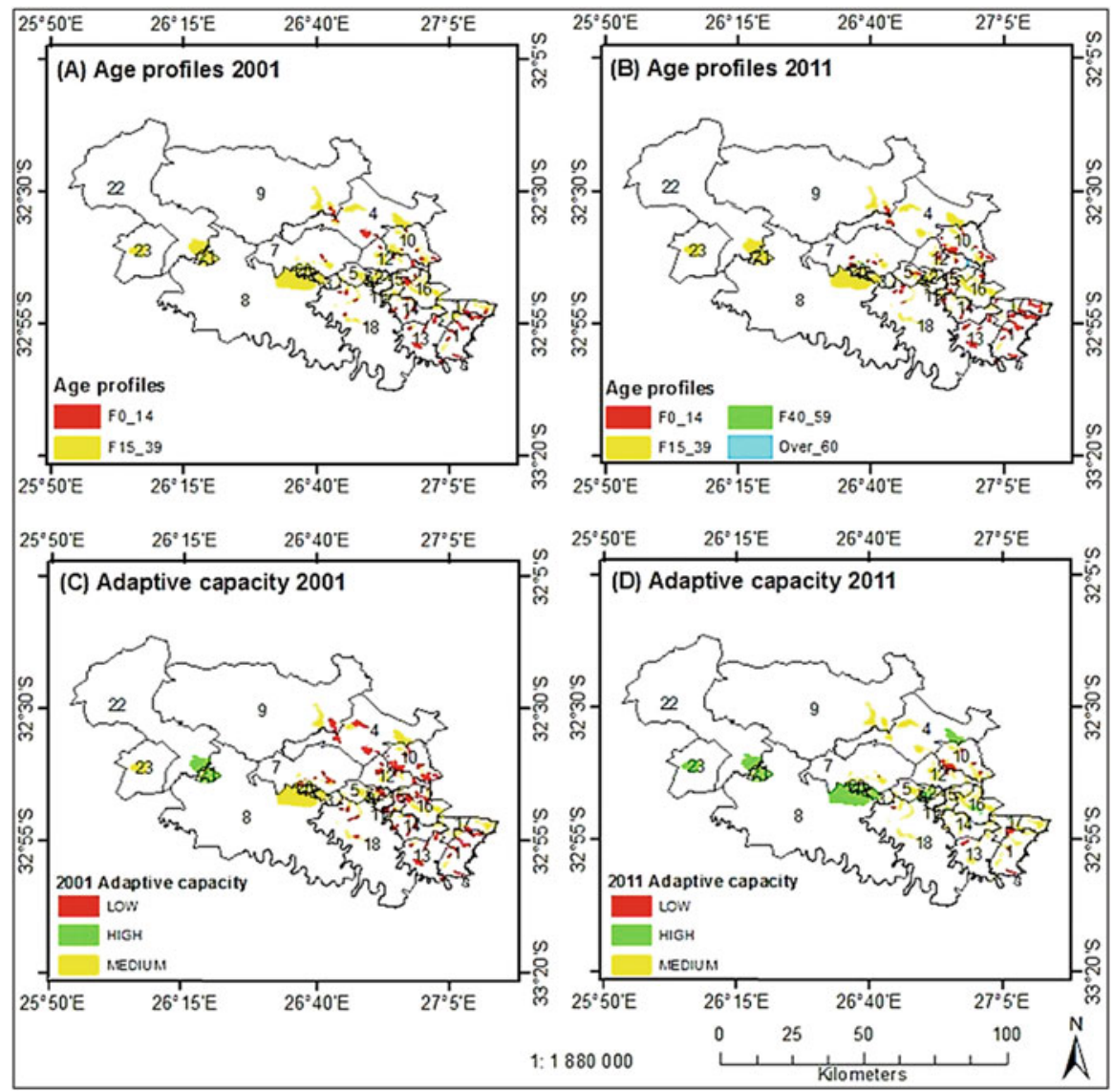

Fig. 3 Age profiles and adaptive capacities of communities in RMLM in 2001 and 2011. (Source: Chari 2020)

those that were identified as having long-term decrease in adaptive capacities (Tables 4 and 5, respectively).

\section{Maps That Were Produced from Data on Water Access, Literacy Levels, and Annual Income Levels That Were Used to Assess Adaptive Capacity for Years 2001 and 2011}

Figure 2 shows spatial distributions of access to water by source type, literacy levels, and annual incomes that were mapped for individual communities in RMLM on the basis of census data for the years 2001 and 2011. Figure 3 shows age profiles for the same communities and their adaptive capacities on the basis of the three-point scale (LOW-MEDIUM-HIGH) that was used to rank the uptake of adaptation interventions by individual communities. The last map (Fig. 4) shows spatial variations in 


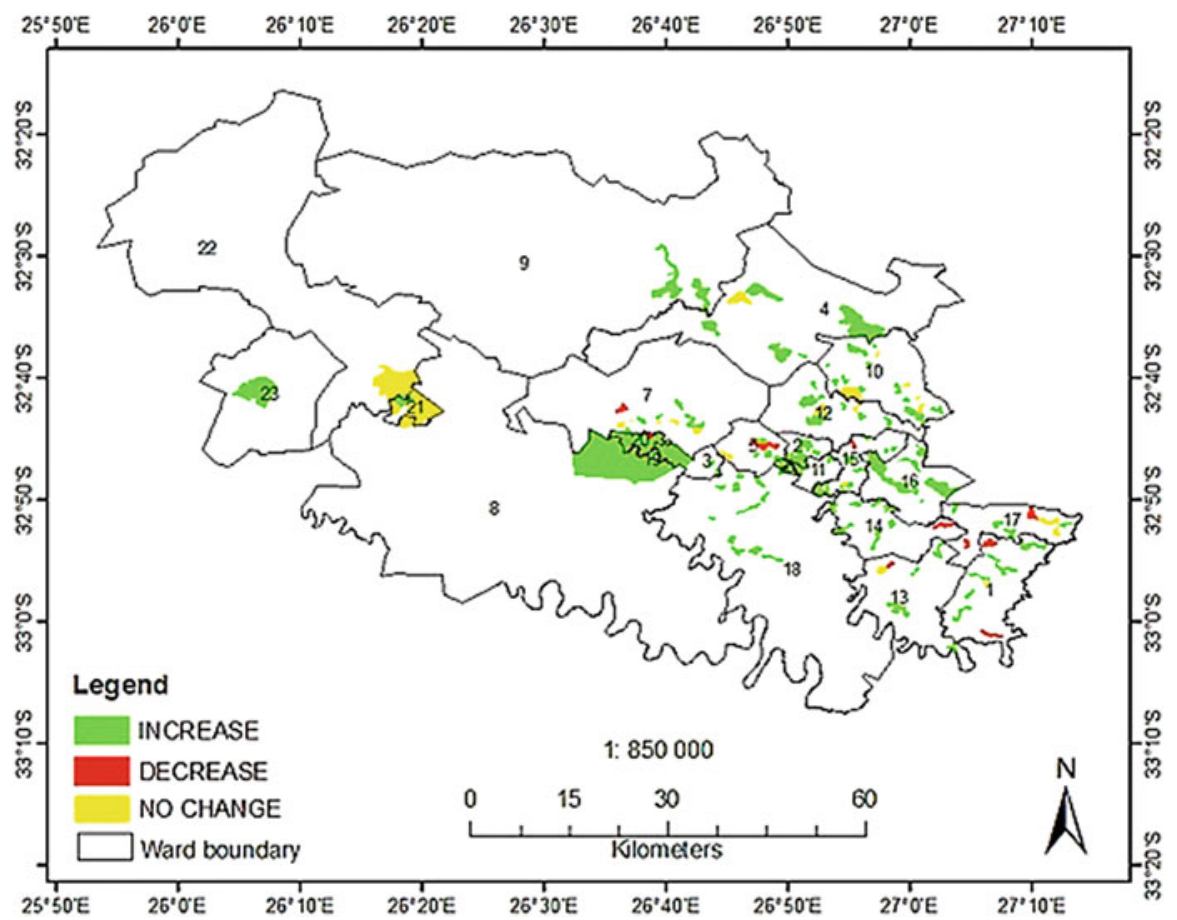

Fig. 4 Changes in adaptive capacities between years 2001 and 2011. (Source: Chari 2020)

Table 4 Communities that were identified as having a long-term decrease in adaptive capacities from 2001 to 2011

\begin{tabular}{l|l}
\hline Name of community by number of ward in which it is located & Ward number \\
\hline MnqabaJames & 1 \\
\hline Qamdobowa & 1 \\
\hline Mgquba & 5 \\
\hline Fernvilla & 7 \\
\hline eMgwanisheni & 13 \\
\hline Newtown & 14 \\
\hline Ncera & 15 \\
\hline Koloni & 17 \\
\hline Zihlahleni & 17 \\
\hline KwaMlalandle & 20 \\
\hline $\mathrm{N}=10$ & \\
\hline
\end{tabular}

Source: Chari 2020

abilities of individual communities to mitigate the adverse effects of climate change by capturing spatial distributions of changes in adaptive capacities that were identified from the ranked adaptive capacity scores in Table 3. 
Table 5 Communities that were identified as having declining/static adaptive capacities in Raymond Mhlaba Local Municipality in 2001 and 2011

\begin{tabular}{l|l|l|l}
\hline \multirow{2}{*}{ Name of community by number of ward in which it is located } & \multicolumn{2}{|l}{ Adaptive capacities } \\
\cline { 2 - 4 } KwaKulile & 1 & 2001 & 2011 \\
\hline Mnqaba James & 1 & LOW & LOW \\
\hline Qamdobowa & 1 & MEDIUM & LOW \\
\hline KwaNacelwane & 7 & LOW & LOW \\
\hline Jomlo & 10 & LOW & LOW \\
\hline Lower Hopefield & 10 & LOW & LOW \\
\hline Machibini & 10 & LOW & LOW \\
\hline Mdeni B & 10 & LOW & LOW \\
\hline Mazotshweni & 12 & LOW & LOW \\
\hline eMgwanisheni & 13 & MEDIUM & LOW \\
\hline KuDikidikana & 13 & LOW & LOW \\
\hline Lebanon & 18 & LOW & LOW \\
\hline $\mathrm{N}=12$ & & & LOW \\
\hline Sour & & & LOW \\
\hline
\end{tabular}

Source: Chari 2020

\section{Tables That Show Adaptive Capacity Levels for Individual Communities by Year Period}

Tables 4 and 5 show communities that were identified as having (a) declining (medium - low) and static (low) adaptive capacities in the 2001 and 2011 census surveys and (b) communities that were identified as having a long-term decrease in adaptive capacity in the 10 years between 2001 and 2011 .

\section{Discussion and Conclusion}

\section{Discussion}

This section discusses the results of this initiative by placing the major findings in a broader context with emphasis being given on the responsiveness of communities to climate change on the basis of the extent to which individual communities were able to access the three indicators that were singled out for investigation and how age profiles influence their adaptive capacities. The section concludes the chapter by stating the methodology's limitations and highlighting its usefulness in tracking adaptation.

\section{Access to Water}

Sources of water by source type in wards 1-23 (Fig. 2a and b) affect the resilience of communities (not shown in Fig. 2a and b) by influencing the availability of water. In 2001 (Fig. 2a), two communities (Teba and KwaNgwevu in ward 7) were severely 
water stressed and obtained water from two nonnatural sources comprising water vendors and water tankers. By 2011 (Fig. 2b), three communities (Msobomvu in ward 12, Allandale in ward 13, and MnqabaJames in ward 1) were identified as severely water stressed, although they still depended on water from the same nonnatural sources as they did in 2001. The increase in the number of communities depending on nonnatural sources from 2 to 3 is indicative of how deteriorating climatic conditions are reducing natural availability of water which is corroborated by the observed occurrence of consecutive droughts in the Eastern Cape province in 1992, 2004, and 2009 (ADM 2010, 2012; IFRC 2004). These scenarios strongly suggest that in this environment, water scarcity is a persistent problem that requires exploration of alternative water sources and a judicious mix of different water saving techniques in order to reduce dependence on costly supplies provided by government and commercial operators.

\section{Literacy Levels}

Figure $2 \mathrm{c}$ and $2 \mathrm{~d}$ indicates spatial variations in levels of schooling. In 2001 (Fig. 2c), two communities (NgqolowaA and Dhlawu) in ward 13 and six communities (Ndindwa, Gqumashe, KwaMemela, Lower Hopefield, Mavuvumezini, and Calderwood) in wards $1,2,3,10,14$, and 18 , respectively, were identified as having no formal schooling. By 2011, only two communities (Mdeni B in ward 5 and Lebanon in ward 13) were identified as having the majority of the population without formal schooling (Fig. 2d). This observation is not only commendable but interesting because it suggests that awareness of climate change issues is increasing as the number of people gaining access to formal education increases. Unfortunately, awareness alone does not automatically translate into increased uptake of actionable adaptation strategies in the absence of enabling factors that facilitate the translation of recommended actions into tangible climate friendly activities because knowing alone without inspiration and capacity to act is inadequate (Adger et al. 2009). Ability to act requires capacity in the form of resources which in the case of RMLM is evidently lacking because of poverty. This asseveration is supported by the 2011 census data which shows that $48.1 \%$ of the people in Nkonkobe and $42 \%$ in Nxuba were unemployed (StatsSA 2014). In view of this consideration and the documented prevalence of poverty in this area, it is not unreasonable to suggest that although literacy improved, effective implementation of climate change adaptation strategies continues to be constrained by lack of a holistic approach that embraces a wide range of enabling factors that determine the ability of communities to meaningfully embrace climate-friendly interventions.

\section{Annual Income Levels}

Figure $2 \mathrm{e}$ and $2 \mathrm{f}$ indicate communities with and without income, respectively, with the latter being destined to be susceptible to most climate change-induced shocks due to lack of access to credit. In year 2001, 51 communities emerged as being dominated by people without any income (Fig. 2e) while 5 communities (Seymour, MdeniA, Magxagxeni, Koloni, and kwaSawu) in wards 4, 7, 10, 17, and 15, respectively, were identified as the poorest in the municipality (Fig. 2f). These results 
are in agreement with the 2011 census data which shows that the majority of people in these communities do not have any sources of income (StatsSA 2014). The nationwide prevalence of this limitation is supported by many researchers (Mkuhlani et al. 2019; Rusere et al. 2019; Mpandeli and Maponya 2013) who report that in the Lambani, Tshakhuma, Rabali, and Tshiombo communities in Limpopo province, most households find rain-fed crop production extremely risky because they cannot afford supplementary irrigation and do not qualify to get external support in the form of agricultural insurance due to widespread lack of reliable sources of income.

\section{Influence of Age Profiles on Resilience}

The identification of communities with different levels of resilience on the basis of age profiles (Fig. 3a and $3 \mathrm{~b}$ ) was based on the reasoning that children and old people have limited capacities to assimilate and implement adaptation strategies by virtue of being economically inactive compared to their economically active counterparts of intermediate age. In year 2001 (Fig. 3a), 37 communities were identified as having the majority of the people in the ages between 0 and 14 years. By year 2011 (Fig. 3b), a total of 46 communities were identified as having the majority of people in the ages between 0 and 14 years with 2 of these communities having the majority of people above 60 years of age while 68 communities had low adaptive capacities in 2001 (Fig. 3c). Although 54 of these communities had improved from low to medium and high adaptive capacities by 2011, this apparent improvement falls short of the desired situation because the downward trend in capacities of two of these communities (eMgwanisheni and MnqabaJames) is actually indicative of the system's inability to effectively mitigate the adverse effects of climate change with additional support for this observation coming from the fact that between 2001 and 2011, $7.5 \%$ of the communities in RMLM were identified as having low or decreasing adaptive capacities (Table 5).

The results presented here are useful because they demonstrate that objectively based geostatistical techniques can be used to aid disaster management by creating space for timely and reliable identification of communities that can be targeted as recipients of appropriately informed adaptation strategies at multiple temporal and spatial scales. In a broader context, the methodology is potentially capable of enhancing adaptation tracking because of its ability to accommodate wide-ranging demographic datasets that are often provided in different and unstandardized formats. This proficiency makes it adaptable to suit different areas of interest and capable of being used to support different stakeholders such as the Global Commission on Adaptation and many others which seek to ensure that adaptation action and support reaches the most vulnerable communities.

\section{Conclusion}

Although the methodology presented in this chapter is admittedly far from being capable of offering a universal solution due to gaps in the availability of data at appropriate spatial and temporal scales and lack of a single unit of analysis that can 
be used to measure or compare adaptation, accessibility of demographic data in most countries still makes it a usable option worth considering because the acquisition of fine-scale data can be prohibitively expensive and time consuming. Even though these challenges are likely to persist for some time into the future, one of the major strengths of the methodology is that it provides an ideal entry point to adaptation tracking at both the national and sub-national levels because its bottom-up basis and firm grounding in a GIS-based framework can accommodate consistent and contextually focused multilevel assessment at different spatial and temporal scales. The other strength of the methodology is that its bottom-up inclination confers a sense of involvement in the decision-making process by creating space for the incorporation of inputs from key stakeholders who are directly involved in and affected by the implementation of adaptation projects. In addition, the methodology's ability to provide a spatially explicit presentation of adaptive capacities offers additional advantages by enabling those interested in adaptation tracking to identify trends in the assimilation and implementation of climate friendly adaptation interventions. The major insight from this initiative is that although data scarcity is often singled out as one of the major constraints confronting adaptation tracking, the geostatistical methodology presented in this chapter provides a workaround approach that can be tapped and used to maximize the utility of different and readily accessible datasets from disparate sources. The take home message is that practitioners, policy-makers, and other stakeholders interested in fast-tracking and enhancing the effectiveness of adaptation interventions stand to benefit by adopting this methodology because it can be easily adapted to effectively track the adoption of adaptation under wideranging situations.

Acknowledgments The authors would like to thank the Water Research Commission's K5/2496/4 project and National Research Foundation (NRF) of South Africa for funding.

\section{References}

Adger WN, Dessai S, Goulden M, Hulme M, Lorenzoni I, Nelson DR, Naess LO, Wolf J, Wreford A (2009) Are there social limits to adaptation to climate change? Clim Chang 93(3):335-354

ADM (2010) Amathole District Municipality State of the District Address. Amathole Community News, pp 1-2. Available http://www.amathole.gov.za/old/attachments/article/70/English Newsletter 2010 June.pdf. Accessed 21 Jan 2019

ADM (2012) Amathole District Municipality 2012-2017 Integrated Development Plan. Available http://www.amathole.gov.za/old/attachments/article/324/FINAL\%20IDP\%202012-2017.pdf. Accessed 04 Feb 2019

ADM (2017) Amathole District Municipality 2017-2020 Integrated Development Plan (IDP) Eastern Cape Socio Economic Consultative Council (ECSECC). Available https://www.ecsecc. org/information-centre/item/amathole-2017-2020-integrated-development-plan-idp. Accessed 28 Jan 2019

Berrang-Ford L, James D, Ford JD, Paterson J (2011) Are we adapting to climate change? Glob Environ Chang 21(1):25-33

Berrang-Ford L, Biesbroek, Ford JD, Lesnikowski A, Tanabe A, Wang FM, Chen C, Hsu A, Hellmann JJ, Pringle P, Grecequet M (2019) Tracking global climate change adaptation among governments. Nat Clim Chang 9:440-449 
Biesbroek G, Swart RJ, Carter TR, Cowan C, Henrichs T, Mela H, Morecroft MD, Rey D (2010) Europe adapts to climate change: comparing national adaptation strategies. Glob Environ Chang 20(3):440-450

Bouroncle C, Imbach P, Rodríguez-Sánchez B, Medellín C, Martinez-Valle A, Läderach P (2017) Mapping climate change adaptive capacity and vulnerability of smallholder agricultural livelihoods in Central America: ranking and descriptive approaches to support adaptation strategies. Clim Chang 141(1):123-137

Brooks N (2011) Tracking adaptation and measuring development. IIED climate change working paper: no. 1. IIED, London

Chari MM (2020) Enhancing adaptive capacities of farmers to climate-induced rainfall variabilities by modelling soil moisture patterns in Raymond Mhlaba Local Municipality, Eastern Cape Province, South Africa. Draft PhD thesis, Department of Geography \& Environmental Science, University of Fort Hare, Alice main campus, South Africa

Chari MM, Hamandawana H, Zhou L (2018) Using geostatistical techniques to map adaptive capacities of resource-poor communities to climate change: a case study of Nkonkobe local municipality, Eastern Cape Province, South Africa. Int J Clim Change Strategies Manage 10 (5):670-688

Conway D, Nicholls RJ, Brown S, Tebboth MG, Adger WN, Ahmad B, Biemans H, Crick F, Lutz AF, De Campos RS, Said M (2019) The need for bottom-up assessments of climate risks and adaptation in climate-sensitive regions. Nat Clim Chang 9:503-511

de Sherbinin A (2016) Remote sensing and socioeconomic data integration: lessons from the NASA socioeconomic data and applications center. CRC Press, Boca Raton

Dinar A, Hassan R, Mendelsohn R, Benhin J (2012) Climate change and agriculture in Africa: impact assessment and adaptation strategies. Routledge. Available https://content.taylorfrancis. com/books/download?dac $=$ C $2011-0-06085-0 \&$ isbn $=9781136569746 \&$ format $=$ googlePreviewPdf. Accessed 10 Apr 2019

Dwesini X (2018) ADM secures 10 trucks for drought relief. Daily Dispatch, South Africa. https:// www.dispatchlive.co.za/news/2018-09-18-adm-secures-10-trucks-for-drought-relief/. Accessed 04 Oct 2019

Engelbrecht F, Adegoke J, Bopape MJ, Naidoo M, Garland R, Thatcher M, McGregor J, Katzfey J, Werner M, Ichoku C, Gatebe C (2015) Projections of rapidly rising surface temperatures over Africa under low mitigation. Environ Res Lett 10(8):85004

FAO (2017) Tracking adaptation in agricultural sectors: Climate change adaptation indicators. Food and Agriculture Organization of the United Nations (FAO), Rome. Available http://www.fao. org/resilience/resources/resources-detail/en/c/1106739/. Accessed 03 April 2019

Ford J, Berrang-Ford L, Lesnikowski A, Barrera M, Heymann S (2013) How to track adaptation to climate change: a typology of approaches for national-level application. Ecol Soc 18(3):40

Ford JD, Berrang-Ford L, Bunce A, McKay C, Irwin M, Pearce T (2015) The status of climate change adaptation in Africa and Asia. Reg Environ Chang 15(5):801-814

Fox KM, Nelson S, Frankenberger TR, Langworthy M (2018) Climate change adaptation in Ethiopia: developing a method to assess program options. In: Resilience, pp 253-265. https:// doi.org/10.1016/B978-0-12-811891-7.00021-9. Elsevier

Gamble JL, Hurley BJ, Schultz PA, Jaglom WS, Krishnan N, Harris M (2013) Climate change and older Americans: state of the science. Environ Health Perspect 121(1):15-22

Gbetibouo GA, Ringler C, Hassan R (2010) Vulnerability of the South African farming sector to climate change and variability: an indicator approach. Nat Res Forum 34(3):175-187

Georgeson L, Maslin M, Poessinouw M, Howard S (2016) Adaptation responses to climate change differ between global megacities. Nat Clim Chang 6(6):584-588

Hamandawana H, Chanda R, Eckardt F (2008) Reappraisal of contemporary perspectives on climate change in southern Africa's Okavango Delta sub-region. J Arid Environ 72(9):17091720

Heltberg R, Bonch-Osmolovskiy M (2011) Mapping vulnerability to climate change. World Bank Policy Research, Washington, DC 
Hlahla S, Nel A, Hill TR (2018) Assessing municipal-level governance responses to climate change in KwaZulu-Natal, South Africa. J Environ Plan Manag 62(6):1089-1107

https://www.greenclimate.fund/countries/south-africa. Accessed 17 Apr 2019

IFRC (International Federation of Red Cross) (2004) South Africa: drought. Available http://www. ifrc.org/docs/appeals/rpts04/ZA040130.pdf. Accessed 03 Jan 2019

IPCC (2014) Climate change 2014: synthesis report. Contribution of Working Groups I, II and III to the fifth assessment report of the Intergovernmental Panel on Climate Change [Core writing team, Pachauri RK, Meyer LA (eds)]. Geneva. Available https://www.ipcc.ch/report/ar5/syr/. Accessed 13 Apr 2019

IPCC (2018) Summary for policymakers. In: Masson-Delmotte V, Zhai P, Pörtner H-O, Roberts D, Skea J, Shukla PR, Pirani A, Moufouma-Okia W, Péan C, Pidcock R, Connors S, Matthews JBR, Chen Y, Zhou X, Gomis MI, Lonnoy E, Maycock MT, Waterfield T (eds) Global warming of $1.5^{\circ} \mathrm{C}$. An IPCC Special report on the impacts of global warming of $1.5^{\circ} \mathrm{C}$ above preindustrial levels and related global greenhouse gas emission pathways, in the context of strengthening the global response to the threat of climate change, sustainable development, and efforts to eradicate poverty. World Meteorological Organization, Geneva, $32 \mathrm{pp}$. Available https://www.ipcc.ch/sr15/chapter/summary-for-policy-makers/. Accessed 23 Nov 2018

Jiri O, Mafongoya P (2017) A synthesis of smallholder farmers' adaptation to climate change in Southern Africa: averting adaptation vacuum. In: Climate change adaptation in Africa. Springer, Cham, pp 247-265. https://doi.org/10.1007/978-3-319-49520-0_16

Juhola S, Kruse S (2015) A framework for analysing regional adaptive capacity assessments: challenges for methodology and policy making. Mitig Adapt Strateg Glob Chang 20(1):99-120

Jury MR (2019) South Africa's future climate: trends and projections. In: Knight J, Rogerson CM (eds) The geography of South Africa. Contemporary changes and new directions. World regional geography book series, vol 4. Springer International Publishing AG, a part of Springer Nature, Cham, pp 305-312

Keskitalo E, Preston B (2019) Research handbook on climate change adaptation policy. Edward Elgar Publishing, Cheltenham/Northampton

Kuwornu JKM (2019) Climate change and Sub-Saharan Africa: the vulnerability and adaptation of food supply chain actors series on climate change and society. Vernon Press, Wilmington

Leal Filho W, de Freitas LE (2018) Climate change adaptation in Latin America. Springer, Cham

Leal Filho W, Esilaba AO, Rao KP, Sridhar G (2015) Adapting African agriculture to climate change. Springer, Berlin, p 233

Leal Filho W, Simane B, Kalangu J, Wuta M, Munishi P, Musiyiwa K (2017) Climate change adaptation in Africa. Climate change management, 1610-2010. Springer, Cham

Lesnikowski A, Ford J, Biesbroek R, Berrang-Ford L, Maillet M, Araos M, Austin SE (2017) What does the Paris Agreement mean for adaptation? Clim Pol 17(7):825-831

Local Government Handbook (2016) The local government handbook: South Africa. http://www. localgovernment.co.za/locals/view/233/Raymond-Mhlaba-Local-Municipality. Accessed 27 Feb 2019

Mkuhlani S, Crespo O, Rusere F, Zhou L, Francis J (2019) Classification of small-scale farmers for improved rainfall variability management in South Africa. Agroeco Sustain Food Syst 1-23. https://doi.org/10.1080/21683565.2018.1537325

Mpandeli NS, Maponya PI (2013) Coping with climate variability in Limpopo Province, South Africa. Peak J Agric Sci 1:54-64

Mukarakate D (2016) Global climate finance - will Africa benefit after Paris?. http://www.africa. undp.org/content/rba/en/home/blog/2016/4/21/Global-Climate-Finance-Will-Africa-BenefitAfter-Paris-.html. Accessed 25 Mar 2019

Ncube M, Madubula N, Ngwenya H, Zinyengere N, Zhou L, Francis J, Mthunzi T, Olivier C, Madzivhandila T (2016) Climate change, household vulnerability and smart agriculture: the case of two South African provinces. Jàmbá J Disaster Risk Stud 8(2):6-8

Ndamase M (2019) ADM again declared a drought disaster area. Daily Dispatch, South Africa. https://www.pressreader.com/south-africa/daily-dispatch/20190710/281522227653276. Accessed 10 Oct 2019 
New M (2018) What the latest assessment on global warming means for southern Africa. Quest 14 (4):12-13

Ngqakamba S (2019) Gift of Givers aids drought-stricken Amathole municipality with bottled water in truckloads. News 24, South Africa. https://www.news24.com/SouthAfrica/News/giftof-givers-aids-drought-stricken-amathole-municipality-with-bottled-water-in-truckloads20190410. Accessed 06 Oct 2019

Nkonkobe Local Municipality (2012) Integrated development plan 2012-2017. http://nkonkobe. gov.za/?q=system/files/filedepot/2/FINAL IDP 2012-2017.pdf. Accessed 23 Jan 2019

Pauw WP, Klein RJ, Mbeva K, Dzebo A, Cassanmagnago D, Rudloff A (2018) Beyond headline mitigation numbers: we need more transparent and comparable NDCs to achieve the Paris Agreement on climate change. Clim Chang 147:23-29

Qiu Y, Zhao X, Fan D, Li S (2019) Geospatial disaggregation of population data in supporting SDG assessments: a case study from Deqing County, China. ISPRS Int J Geo Inf 8(8):356

Rankoana SA (2019) Food security under unreliable rainfall: the case study of a rural community in Limpopo Province, South Africa. J Water Clim Change. https://doi.org/10.2166/wcc.2019.109

Rusere F, Mkuhlani S, Crespo O, Dicks LV (2019) Developing pathways to improve smallholder agricultural productivity through ecological intensification technologies in semi-arid Limpopo, South Africa. Afr J Sci Technol Innov Dev 1-11. https://doi.org/10.1080/ 20421338.2018.1550936

Sarkodie SA, Strezov V (2019) Economic, social and governance adaptation readiness for mitigation of climate change vulnerability: evidence from 192 countries. Sci Total Environ 656:150 164

Schensul D, Martine G, Guzmán JM (2013) The demography of adaptation to climate change. UNFPA, IIED, and El Colegio de México, New York

Statistics South Africa (2014) Census 2011 provincial profile: Eastern Cape. Report No. 03-01-71. http://www.statssa.gov.za/publications/Report-03-01-71/Report-03-01-712011.pdf. Accessed 20 July 2019

Taylor A (2016) Institutional inertia in a changing climate. Int J Clim Change Strategies Manage 8 (2):194-211

Tompkins EL, Vincent K, Nicholls RJ, Suckall N (2018) Documenting the state of adaptation for the global stocktake of the Paris Agreement. Wiley Interdiscip Rev Clim Chang 9(5):e545

Van Aalst MK, Cannon T, Burton I (2008) Community level adaptation to climate change: the potential role of participatory community risk assessment. Glob Environ Chang 18(1):165-179

Wall E, Marzall K (2006) Adaptive capacity for climate change in Canadian rural communities. Local Environ 11(4):373-397

Weis SW, Agostini VN, Roth LM, Gilmer B, Schill SR, Knowles JE, Blyther R (2016) Assessing vulnerability: an integrated approach for mapping adaptive capacity, sensitivity, and exposure. Clim Chang 136(3):615-629

World Bank (2014) Turn down the heat: confronting the new climate normal. World Bank Publications, Washington, DC. www.statssa.gov.za. Accessed 13 Mar2019

Zhou L, Sibanda M, Musemwa L, Ndhleve S (2016) Vulnerability to climate change related disasters in the Eastern Cape Province: an application of the Household Vulnerability Index (HVI). J Hum Ecol 56(3):335-353

Ziervogel G, New M, Archer van Garderen E, Midgley G, Taylor A, Hamann R, Stuart-Hill S, Myers J, Warburton M (2014) Climate change impacts and adaptation in South Africa. Wiley Interdiscip Rev Clim Chang 5(5):605-620 
Open Access This chapter is licensed under the terms of the Creative Commons Attribution 4.0 International License (http://creativecommons.org/licenses/by/4.0/), which permits use, sharing, adaptation, distribution and reproduction in any medium or format, as long as you give appropriate credit to the original author(s) and the source, provide a link to the Creative Commons license and indicate if changes were made.

The images or other third party material in this chapter are included in the chapter's Creative Commons license, unless indicated otherwise in a credit line to the material. If material is not included in the chapter's Creative Commons license and your intended use is not permitted by statutory regulation or exceeds the permitted use, you will need to obtain permission directly from the copyright holder.

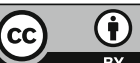

